\title{
The emergency and stability of institutions Introduction and overview
}

\author{
Maarten C.W. Janssen ${ }^{\mathrm{a}, *}$, Claude Ménard ${ }^{\mathrm{b}}$ \\ ${ }^{a}$ Erasmus University Rotterdam, Department of Economics, P.O. Box 1738, 3000 DR Rotterdam, The \\ Netherlands \\ ${ }^{\mathrm{b}}$ Université de Paris I-Pantheon-Sorbonne, Centre ATOM, 90 rue de Tolbiac, 75634 Paris Cedex 13, \\ France
}

This special issue contains seven papers on The Emergence and Stability of Institutions. Recently, this topic has drawn attention from different domains of economic analysis, some so far away from each other as, for example, game theory and economic history. The papers collected here reflect this variety. They can, however, be regarded as a (Wittgensteinian) family: each paper is related to several other papers. Although there is not one theme (apart from the broad topic of this issue) that is developed in all papers, there are four themes that are dealt with in one way or another in the collection as a whole: (i) coordination problems, (ii) emergence, (iii) learning and belief change, (iv) persistence. Subsets of papers can be grouped around these themes.

Coordination problems within firms with work norms as their solution are studied at a micro level by Goyal and Janssen. Two papers deal with coordination at a social level. (a) The problem of how to coordinate exchange with money as its solution is the focus of analysis by Van Ees and Garretsen; (b) Sugden analyses the problem of coordination in societies with social conventions as their solution. At an intermediate level, the problem of coordination among firms in a market, or between different markets, with the solution of specific institutional arrangements is analyzed in Ménard, Bianchi and De Marchi.

The issue of emergence is analyzed as a consequence of existing tensions of one sort or the other. De Marchi shows that tension between different market forms creates new market forms. Orléan demonstrates how a public opinion

\footnotetext{
${ }^{*}$ Corresponding author
} 
emerges in a world where different opinions compete. Sugden studies conditions under which a convention emerges in social situations where multiple conventions compete. Finally, Bianchi (and to some extent Ménard) shows how, among other things, new market forms emerge when firms compete

With respect to the issue of learning and belief change two approaches can be discerned. A first approach, exemplified hy Goyal and Janssen, and Orléan, focuses on the question whether, and if so how, individuals learn or change beliefs. Their results point at possible inefficiencies (in terms of pay-offs or loss of information) even if individuals are rational. The second approach, exemplified by the papers by Bianchi, and Van Ees and Garretsen, emphasize more the institutional environment in which firms and markets operate. This second approach stresses the importance of trial-and-error and historical contingencies for an understanding of the emergence of actual institutional arrangements or conventions (money).

Finally, the issue of persistence is also analyzed from two distinct points of view. Sugden, Orléan, and Goyal and Janssen analyze the persistence question in terms of the incentives individual actors have to conform (not to induce change). This is exemplified by the analysis of Goyal and Janssen who show that the lack of incentives of a worker in an organization to reveal useful information might lead certain conventions to persist. De Marchi, and Van Ees and Garretsen, on the other hand, investigate the issue of persistence more in terms of the institutional and historical conditions that are necessary for persistence. The importance that Van Ees and Garretsen attach to the formal institution of a Central Bank in providing trust that is necessary to give money its general acceptability is illustrative in this respect.

Of course, each paper contributes to its own domain of analysis. Part of the novelty of the papers lies, however, in the fact that they approach the issues they address from the point of view of the common theme of this special issue. This is what creates the family relation between these papers on The Emergence and Stability of Institutions. A few remarks on the content of the individual papers will conclude this introduction.

The paper by Ménard argues that the basic terms of the New Institutional Economics research program, namely markets, organizations and institutions, are not clearly defined. He makes an attempt at conceptual clarification, extending the distinction between institutional environment and institutional arrangements. $\mathrm{He}$ also emphasizes the role of hybrid forms as well as the necessity to maintain a discrete conceptual structure. In her paper, Bianchi develops the idea of the interaction between markets and organizations (firms) further. She points out that firms and markets create and recreate each other in a never ending flux. Key terms in her paper are the creation of capabilities, leaming and innovation. She contrasts her approach with a transaction cost approach. De Marchi's paper on the history of the art market in 17th century Holland is in some important ways closely linked to Bianchi's analysis. He argues that the tension between two forms of institutional 
arrangements, namely two forms of markets, creates new arrangements. This argument is supported by a detailed study of the historical development of different selling practices in two cities, Amsterdam and Haarlem.

The papers by Goyal and Janssen, and Sugden provide a game theoretic approach to some issues concerning the stability of conventions. Goyal and Janssen study the role conventions (work norms) play in firms to solve some coordination problems. They show that there is a tendency for such conventions to persist even when they support inefficient outcomes. As a means of investigating the (in) stability of social conventions, Sugden inquires into the conditions under which different social conventions can coexist together. He employs evolutionary game theoretic techniques to argue that coexistence is indeed a possible stable situation if each of these conventions is used in a different domain of social interactions.

The papers by Orléan, and Van Ees and Garretsen look at conventions in financial markets and conventional aspects of the use of money, respectively. Orléan underlines the importance of the commonality of expectations in defining conventions. He goes on studying how this commonality of expectations emerges and whether it is stable in a general model that probably best represents financial markets. Van Ees and Garretsen argue that one of the most important features of money is that it facilitates coordination of economic activities. Their aim is to investigate the implications for monetary theory of the idea that the general acceptability of money is a convention. They show that money is essentially rooted in history and that it is not accidental that it has emerged together with formal institutions like Central Banks. They contrast their ideas with approaches to monetary theory that are based on general equilibrium or game theory.

The variety of the set of papers and of the methodologies involved reflects the diversity of approaches that can be used to study the emergence and stability of institutions. In our view, this diversity is a clear indication of how crucial the questions are, and how lively the associated research.

\section{Acknowledgements}

We would like to thank the Catholic University of Louvain and the SPES-program of the European Union for their financial support. We would like to thank especially Michel de Vroey for his continuous support in organizing the workshop. 